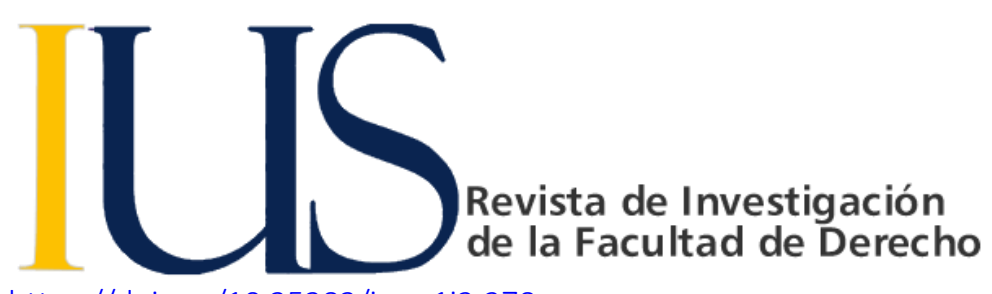

\title{
LIMITES A LAS COMPETENCIAS DEL TRIBUNAL CONSTITUCIONAL COMO ORGANISMO CONTRALOR DEL ORDEN CONSTITUCIONAL
}

\author{
Manuel O. Tafur ${ }^{1}$
}

\begin{tabular}{l}
\hline INFORMACIÓN DEL ARTÍCULO \\
\hline Historia del artículo: \\
Recibido el 05 de agosto de 2019 \\
Aceptado el 24 de setiembre de 2019 \\
\hline
\end{tabular}

Palabras clave:

Tribunal constitucional

límite de poderes

competencia

\section{RESUMEN}

Uno de los problemas que ha merecido innumerables críticas tanto del sector especializado como de la comunidad jurídica en general, y que ha motivado nuestra atención, pues no es ajeno al contexto democrático en el que se desarrolla nuestro país, se refiere a las constantes fricciones originadas con otros órganos integrantes del sistema constitucional (por ejemplo la reciente sentencia emitida en el Exp. 0020-2015-PI/TC, mediante la cual se declara la inconstitucionalidad del artículo 46 de la Ley 27785 que regulaba la facultad sancionatoria de la Contraloría General de la República), a partir de las cuales se ha propalado una posición casi mayoritaria respecto del "excesivo poder" con el que cuenta nuestro Tribunal Constitucional, reconocido como intérprete privilegiado de la Constitución, cuya función es la de preservar el orden constitucional y por ende el equilibrio de poderes; y si bien actúa con autonomía e independencia (principios reconocidos por su Ley Orgánica), su labor no tiene por qué estar exenta de cuestionamientos.

Limits to the competences of the constitutional court as a contracting organism of the constitutional order

\section{ABSTRACT}

\section{Keywords:}

Constitutional Court

powers limit

competition
One of the problems that has deserved innumerable criticisms of both the specialized sector and the legal community in general, and that has motivated our attention, since it is not alien to the democratic context in which our country develops, refers to the constant frictions caused with other constituent bodies of the constitutional system (for example, the recent ruling issued in Exp. 0020-2015-PI / TC, which declares the unconstitutionality of article 46 of Law 27785 regulating the sanctioning power of the Comptroller General of the Republic), from which an almost majority position has been propagated regarding the "excessive power" that our Constitutional Court has, recognized as a privileged interpreter of the Constitution, whose function is to preserve

\footnotetext{
${ }^{1}$ Abogado. Profesor adscrito al departamento de Ciencias Jurídicas de la Universidad Católica Santo Toribio de Mogrovejo. Chiclayo, Perú. Contacto: mtafur@usat.edu.pe, Orcid: 0000-0002-0113-0929
} 
the constitutional order and therefore the balance of powers; and although it acts with autonomy and independence (principles recognized by its Organic Law), its work does not have to be free of questions.

\section{Introducción}

Conforme se ha ido avanzando en la tutela de los derechos fundamentales y en la vigencia efectiva de los principios del Estado Constitucional, se han ido escuchando -cada vez con mayor intensidad- voces críticas de la actuación del Tribunal Constitucional peruano, expresando que ha ido demasiado lejos, que se ha excedido en sus atribuciones y que se ha convertido en un legislador positivo que pretende desplazar o desautorizar al Congreso; así como inmiscuirse en asuntos que no son de su directa competencia; posturas que en su versión extrema han sustentado un intervencionismo directo en sus competencias, aduciendo el mismo argumento -cuasi uniforme- que ha venido sustentando las decisiones de este colegiado, es decir de la inexistencia de zonas exoneradas de control en un Estado Democrático y Constitucional de Derechos o -al menos- del que se precie de serlo.

Por ello, es necesario identificar el 'eje de acción' del Tribunal Constitucional peruano a fin de evitar que en "cumplimiento de sus atribuciones", sea pasible de causar interferencias en las competencias de otros órganos constitucionales, propiciando inseguridad jurídica, lo cual resulta incongruente con su labor intrínseca.

Qué duda cabe entonces, que el problema se evidencia materialmente en muchas de las decisiones emitidas por este colegiado constitucional, que a lo largo de sus distintas conformaciones, han sido y seguirán siendo objeto de crítica (especializada o no), por lo que nos proponemos plantear una propuesta que justifique, desde la naturaleza reconocida a éste órgano constitucionalmente autónomo, la necesidad de autolimitar su actuación; pues desde una mirada crítica a la justicia constitucional, no podemos negar algunos excesos valorativos de interpretación, así como una extralimitación en el uso de sus competencias. De este modo, nos proponemos pasar revista a sus facultades interpretativas desde un enfoque restrictivo o activista; y en qué modo ello incide sobre la interpretación constitucional realizada por dicho intérprete privilegiado, contando con suficientes elementos de juicio para realizar una propuesta que permita un mayor desarrollo de la justicia constitucional.

\section{EL ORIGEN DEL TRIBUNAL CONSTITUCIONAL PERUANO Y SU VIGENCIA EN EL MARCO DE UN ESTADO CONSTITUCIONAL DE DERECHO}

El Perú a nivel de Latinoamérica fue el pionero en la incorporación del Tribunal Constitucional en la Constitución de 1979; sin embargo, a pesar de su primacía temporal con respecto a otros países de la región, su trayectoria no estuvo bien definida; ello por cuanto fue concebido como un organismo para luchar contra la ineficacia del Poder Judicial.

Consideremos que la Constitución de 1979 nace al finalizar el gobierno militar de 12 años del General Juan Velasco Alvarado, en el que se produjeron diversos atropellos a los derechos humanos, sin que el Poder Judicial hubiese resistido eficientemente los excesos propios de dicho gobierno de facto; entonces la creación de un Tribunal independiente en nuestro país fue prevista inicialmente como una solución al problema. Garcia (1988) indica que, la iniciativa fue abordada por Javier Valle Riestra quien, influenciado por su tiempo de exilio en España, propuso la idea de crear un poder al lado del aparato judicial, un ente libre de burocracia que tuviera a su cargo el control de la Constitución y la defensa de los Derechos Humanos a través de determinadas atribuciones.

Fernández (2001) indica que el Perú, constitucionaliza un Tribunal de esta naturaleza bajo el rótulo de Tribunal de Garantías Constitucionales, lo que acontece en la Constitución del 12 de julio de 1979, el que posteriormente sería objeto de desarrollo por intermedio de la Ley $N^{\circ}$ 23385, Ley Orgánica del Tribunal de Garantías Constitucionales, norma por cierto, bastante influida por la Ley Orgánica del Tribunal Constitucional español.

En el año 1979, entonces, se produjeron una serie de cambios en la sociedad peruana, el Perú salía de un gobierno de facto y se encontraba en el trance de aprobar un nuevo texto constitucional, en el cual se acogía un amplio catálogo de derechos, en medio de ello se genera la necesidad de garantizar la protección de los preceptos constitucionales en general, y de los derechos fundamentales en particular; sin embargo, como por aquella época imperaba una sensación de desconfianza en la jurisdicción ordinaria, se temía que éste Tribunal no cumpliera con aquella responsabilidad, por lo que su grado de aceptación en la ciudadanía no mostraba tampoco un panorama positivo; contexto en el que se hace fácil comprender la adopción de un 
modelo mixto, dual o paralelo del control de constitucionalidad implementado en nuestro país (previsto en el artículo. 236 de la Constitución de 1979) que determinaba al efecto que "en caso de incompatibilidad entre una norma constitucional y una legal ordinaria, el juez prefiere la primera".

Admitida así la coexistencia de un control de constitucionalidad concentrado en el Tribunal de Garantías y de un control difuso en la vía judicial, una de las cuestiones que impidió su posicionamiento en el sistema constitucional se basó en la poca vinculación que, en la práctica, generaron sus decisiones frente a los jueces y tribunales ordinarios; pues a pesar de parecer incuestionable que allí donde existía un Tribunal de esta naturaleza, éste era el llamado a ser el "intérprete supremo de la Constitución", no siempre los órganos jurisdiccionales ordinarios atendieron la jurisprudencia del Tribunal de Garantías Constitucionales.

Teniendo en consideración que la vigencia de la Constitución de 1979 se extendió hasta el 05 de abril de 1992, el Tribunal de Garantías Constitucionales cesó en funciones en la misma fecha, siendo clausurado como consecuencia de los hechos registrados por aquella época, y a pesar que la década en la que desarrolló funciones (1982-1992), la realidad de los derechos y libertades en el Perú se caracterizó también por una frecuente violación de los derechos humanos, debido al accionar de grupos subversivos en nuestro país como Sendero Luminoso y el MRTA, así como la acción represiva ilegal (en su mayoría) de las Fuerzas Armadas; y además, por la profunda crisis económica, social e institucional que fomentaba despidos laborales y la arbitrariedad de las autoridades públicas y privadas, su producción (sentencias emitidas en materia de derechos fundamentales) fue escasa, equivalente a 576 recursos casatorios en las acciones de amparo y sobre todo de los hábeas corpus. (Landa, 2011, 14-15).

Luego, con motivo del autogolpe de 1992 fomentado por el entonces Presidente de la República, Ing. Alberto Fujimori Fujimori, se creó una nueva Constitución en 1993, donde se procuró mantener en esencia el modelo de la Constitución de 1979, con la presencia de ciertas diferencias, tales como la modificación del nombre de éste órgano por el de "Tribunal Constitucional", ubicándolo en el esquema constitucional de separación de poderes como el intérprete privilegiado de la Constitución, confiándosele la defensa del principio de supremacía constitucional, además de la protección de los derechos constitucionales de los ciudadanos; con competencias para resolver en última y definitiva instancia las resoluciones denegatorias en los procesos constitucionales de la libertad (Hábeas Corpus, Amparo,
Hábeas Data y Cumplimiento), conocer en instancia única la acción de inconstitucionalidad, así como los conflictos de competencias y atribuciones asignadas por la Constitución o las leyes orgánicas a los Poderes del Estado, los órganos constitucionales y/o los gobiernos regionales o municipales (artículo. 202 de la Constitución en concordancia con el artículo 109 de la Ley 28237); sin embargo, durante su vigencia ha mostrado evidencias de falta de independencia y de "aparente" abuso de sus atribuciones, asumiendo en ocasiones facultades más de sometimiento que de control respecto a los distintos decisiones emitidas tanto por el poder judicial, el ejecutivo o el Congreso de la República, creando un ambiente de inestabilidad y de fricción entre los poderes del estado.

Este Tribunal, configurado con la oposición de la mayoría fujimorista de ese entonces, fue instalado en 1995 y el partido de gobierno, fiel a su estilo de no tolerar «pesos y contrapesos» en el ejercicio del poder, no tardó mucho tiempo en ponerle defenestrarlo, en 1997, destituyendo a los tres magistrados que habían optado por no someterse al régimen: Delia Revoredo Marsano, Manuel Aguirre Roca y Guillermo Rey Terry; así, aun cuando el Tribunal Constitucional siguió funcionando, quedó claramente disminuido y desacreditado.

Solo con la caída del régimen fujimorista y el inicio de la transición democrática bajo la Presidencia de Valentín Paniagua en el 2001, inició su recuperación con el retorno de los tres magistrados arbitrariamente destituidos; en mayo del 2002 el Congreso, mediante Resolución Legislativa № 017-2001-CR, designó a cuatro nuevos magistrados como miembros del TC: Javier Alva Orlandini, Víctor García Toma, Magdiel Gonzales Ojeda y Juan Bardelli Lartirigoyen, ello permitió contar con una nueva conformación del Tribunal Constitucional, cuya jurisprudencia ha constituido un elemento decisivo para "reinterpretar" los alcances de la Constitución de 1993 (Abad, 2010, 81).

A partir de ese momento el Tribunal Constitucional puso en marcha una rápida y fructífera recuperación institucional.

Actualmente el Tribunal Constitucional está conformado por los magistrados Ernesto Blume Fortini, Eloy Espinoza-Saldaña Barrera, Marianella Ledesma Narváez, Manuel Miranda Canales, Carlos Ramos Núñez, José Luis Sardón de Taboada, elegidos por el Congreso de la República en junio del 2014, y completado por Raúl Ferrero Costa quien remplazó al magistrado Óscar Urviola, generación que según Samuel Abad, constituyó en su momento la esperanza 
de un cambio que deje atrás los errores del pasado y fortalezca su legitimidad (Abad, 2016,83)

Autores nacionales como Eto Cruz (2011), han precisado algunas consideraciones en relación a las funciones previstas para el Tribunal Constitucional en la Constitución Política de 1993 (artículo 201) dentro de un Estado Constitucional de Derecho:

Advirtiendo que su desarrollo histórico en el Perú, ha influido en la determinación de una serie de características y funciones que lo identifican y que estructuran su naturaleza; así, en primer lugar, se le considera un poder constituyente constituido, siendo catalogado como el supremo órgano de control e interpretación de constitucionalidad, encargándose de la acción hermenéutica e integradora, es decir, declara y establece el contenido de los valores, principios y normas contenidas en la Constitución; en segundo lugar, es autónomo e independiente, por cuanto el ejercicio de sus funciones $y$ atribuciones no depende de ningún órgano constitucional; en tercer lugar, cumple una función de racionalizar el ejercicio del poder público y privado, mediante el cuidado del respeto y la protección de los derechos fundamentales de las personas naturales $y$ jurídicas; en cuarto lugar, cumple el deber de integrar los vacíos normativos, siendo reconocida su función normativa mediante el artículo $45^{\circ}$ de la Constitución; y finalmente, cumple una función de componedor de conflictos sociales $(p, 125)$.

Landa (2011), por su parte, en atención a la posición particular que el Tribunal Constitucional Peruano ocupa en el esquema constitucional de división de poderes, le reconoce una naturaleza compleja, pues se puede caracterizar como un órgano constitucional y jurisdiccional a la vez, e inclusive para otros autores, tendría también la naturaleza de un órgano político.

Así, los tribunales constitucionales, gozando de autonomía e independencia, interpretan con autoridad la Constitución, de acuerdo a los principios y valores que la informan, interpretación que los operadores jurídicos deben observar (conforme lo establece el artículo VI del Título Preliminar del Código Procesal Constitucional).

\section{MISIÓN DE LOS TRIBUNALES CONSTITUCIONALES.}

Sobre la misión principal de los tribunales constitucionales, Kelsen (1974) en su famoso ensayo de 1928 sobre la jurisdicción constitucional, expresó:

Una constitución a la que le falta la garantía de anulabilidad de los actos inconstitucionales no es plenamente obligatoria en su sentido técnico (...) Una constitución en la que los actos inconstitucionales y en particular las leyes inconstitucionales se mantienen válidos -no pudiéndose anular su inconstitucionalidad - equivale más o menos, desde el punto de vista estrictamente jurídico, a un deseo sin fuerza obligatoria" ( $p, 510)$

A esta aseveración hay que agregar que tal garantía de defensa de la constitución no existe, sino cuando la declaratoria de inconstitucionalidad corresponde a un órgano completamente diferente e independiente de aquel que produjo la norma inconstitucional.

El desarrollo de la Justicia Constitucional en Europa (principalmente luego de las consecuencias generadas por la Segunda Guerra Mundial) y su recepción en América Latina a partir de la Convención Americana de Derechos Humanos (1969), pone de manifiesto la segunda misión de los Tribunales Constitucionales latinoamericanos, esto es defender los derechos fundamentales de la persona, declarando su existencia -precisamente delimitando su contenido constitucionalmente protegido- así como adoptando mecanismos eficientes para su protección como lo son los procesos constitucionales de la libertad (amparo, cumplimiento, habeas data y habeas corpus).

Smend, citado por Monroy Cabra (2004), asigna a los tribunales constitucionales una triple tarea:

Por una parte, crea orden en el amplio espacio de las cuestiones jurídico constitucionales, en las que sólo puede crear un orden auténtico una justicia independiente del más alto rango; en segundo lugar, fortalece las bases de nuestra existencia política, en la que nos permite a los ciudadanos experimentar la vivencia de la condición de Estado de Derecho de nuestra comunidad y de la dignidad garantizada de ciudadanos libres; finalmente, lucha por el imperio de los derechos y los bienes al tomar como motivación expresa de sus decisiones estos más altos valores de la tierra $(p, 30)$.

Lo anterior no hace más que sustentar, lo que ha venido a identificarse como una tercera misión, aunque consideramos que es precisamente el sustento que faculta al Tribunal Constitucional a cumplir las dos anteriormente descritas, es decir, el control del ejercicio del poder del Estado, convirtiéndolo en un verdadero defensor del régimen democrático en un Estado Constitucional de Derecho; lo cual en buena medida nos conduce a la disyuntiva, de afirmar o negar la posibilidad de controlar al controlador; y de ser admisible dicho control, como es que éste se materializa.

\section{EL TRIBUNAL CONSTITUCIONAL COMO ÓRGANO DE CONTROL DEL PODER}


A diferencia de la tesis planteada por Montesquieu (s.f) en su obra más representativa, en la actualidad resulta evidente que más que una diferenciación estructural del poder, es posible identificar funciones principales atribuibles a las instituciones que conforman el aparato estatal, esto es: a) La Función Ejecutiva, propia de las instituciones cuya decisión vinculante obliga a un ciudadano, o un grupo de ellos, a adoptar o evitar una determinada conducta; b) La Función Legislativa, la cual fundamenta la decisión vinculante, dotándola de parámetros, esto es, define los objetivos y procedimientos de cada decisión, reflejándose en leyes, decretos y otros; y, c) La Función Judicial, que se encarga de dirimir las controversias originadas por la interpretación de las normas que rigen la sociedad o la idoneidad de su aplicación, concluyendo en una determinada solución que se aplica al caso en concreto; el fundamento de esta división funcional asumida por las diferentes instituciones es de naturaleza política; pues, recordando la historia del desenvolvimiento de la separación de poderes, nos remontarnos al origen de la tradición del Estado Liberal, donde se luchaba contra la concentración de poder en una sola persona o institución, en ese entonces la monarquía absoluta, por lo que pensadores como Locke y Montesquieu, estaban convencidos que la única forma de evitar el ejercicio abusivo del poder era, con su distribución a más de una institución.

Landa (2011), en ese sentido, adiciona que la relevancia de la existencia de un Tribunal Constitucional radica en que dicha institución está encargada de hacer el control constitucional de las leyes, formando parte de este sistema de separación y balance, transformando el clásico modelo (división de poderes); en ese orden de ideas, el Tribunal Constitucional en la STC 0005-2007$\mathrm{PI} / \mathrm{TC}$ (fundamento Jurídico 14-23), refiriéndose al "Principio Democrático en el Estado Constitucional", ha establecido que dos son los principios sobre los cuales se sustenta su facultad de control del poder:

“... [el Principio Democrático en el Estado Constitucional] se sustenta en lo previsto en el artículo $43^{\circ}$ de la Constitución, el cual alude tanto al reconocimiento de que toda competencia, atribución o facultad de los poderes constituidos emana del pueblo (principio político de soberanía popular) y de su voluntad plasmada en la Norma Fundamental del Estado (principio jurídico de supremacía constitucional), como a la necesidad de que dicho reconocimiento originario se proyecte como una realidad constante en la vida social del Estado, de manera tal que, a partir de la institucionalización de los cauces respectivos, cada persona, individual o colectivamente considerada, goce plenamente de la capacidad de participar de manera activa "en la vida política, económica, social y cultural de la Nación", según reconoce y exige el artículo 2ㅇ 17 de la Constitución..."

Este principio a su vez se sustenta en el Principio Derecho de Dignidad de las personas, considerado como el inicio y fin del Estado, garantizando así su participación en la voluntad político-estatal, lo que constituye el presupuesto indispensable para garantizar el máximo respeto a la totalidad de sus derechos constitucionales.

En ese orden de ideas, el modelo de democracia en un Estado Constitucional se sustenta en la soberanía del pueblo, representada por el Parlamento, cuyas facultades no son absolutas sino relativas pues se encuentran limitadas por la Constitución, en tanto norma jurídica suprema, de modo que las mayorías parlamentarias no pueden desconocer las competencias y los límites formales y materiales establecidos en dicha norma.

“....En el Estado Constitucional, si bien se exige el respeto al principio democrático también se exige el control y balance entre los poderes del Estado, si bien se exige el respeto a las decisiones de las mayorías también se exige que tales decisiones no desconozcan los derechos de las minorías, pues el poder de la mayoría solo adquirirá legitimidad democrática cuando permita la participación de las minorías y reconozca los derechos de estas; y finalmente, si bien se exige mayor participación de los ciudadanos en el Estado, también se exige mayor libertad frente al Estado. La participación del pueblo -y del Parlamento- en el gobierno en un Estado Constitucional exige que tal participación sea realizada respetando fundamentalmente los derechos constitucionales y el control y el balance entre los poderes del Estado..."

Este control del poder al que se refiere el Tribunal Constitucional, parte de una concepción sustentada esencialmente en evitar que quien ejerza funciones administrativas o legislativas realice la función jurisdiccional, y con ello se desconozcan los derechos y las libertades fundamentales; descartando su acepción clásica, esto es la separación tajante y sin relaciones entre los poderes del Estado, sino más bien como una suerte de checks and balances of powers, así como de coordinación y cooperación entre ellos, garantizando la independencia y autonomía de los órganos estatales, lo que no implica que éstos actúen de manera aislada y con compartimentos estancos, cuyas funciones deben ser controladas entre sí. 
En conclusión resulta más adecuado hablar de separación de funciones básicas del Estado, limitándose recíprocamente, lo que constituye una garantía para los derechos constitucionalmente reconocidos e, idénticamente, para limitar el poder frente al absolutismo y la dictadura, en sintonía con ello la Constitución peruana de 1993, recoge expresamente este principio fundamental en el artículo $43^{\circ}$ del Título II: Del Estado y la Nación, al establecer que el gobierno de la República del Perú “(...) se organiza según el principio de separación de poderes (...)".

Aceptar que en un Estado Democrático y Constitucional de Derecho existe un control recíproco de las funciones del Estado, nos genera - en cierta medida- la interrogante si es que las tres merecen el mismo nivel de atención; sin embargo, es el propio Tribunal, que en la sentencia en comento ha interpretado que es la función jurisdiccional que merece mayor atención, pues constituye la garantía última para la protección de la libertad de las personas frente a una actuación arbitraria del Poder Ejecutivo o el Poder Legislativo.

Ahora, otra conclusión que es posible advertir es que en un Estado Democrático y Constitucional de Derecho, el Poder Constituyente ha previsto funciones específicas para los órganos constitucionales, sin desconocer, que aquí también se materialice el principio de separación de poderes con la división entre órganos de decisión política (parlamento y gobierno) y los órganos de decisión jurisdiccional (judicatura ordinaria y constitucional, entre otros).

La facultad de control que ejerce el Tribunal Constitucional peruano alcanza, además hasta los organismos constitucionalmente autónomos, creados de manera expresa por el poder constituyente y que funcionan independientemente de los poderes del Estado, y si bien sus titulares son elegidos por éstos y gozan de prerrogativas e inmunidades, mantienen autonomía administrativa, presupuestal y normativa con competencias a nivel nacional; por ende, pueden originarse conflictos competenciales en la actuación no solo entrés éstos organismos, sino además entre ellos y los demás poderes públicos, situación que eventualmente puede llevar a la interposición de una acción para dirimir el conflicto competencial.

Estos organismos reconocidos por la Constitución de 1993 son: el Tribunal Constitucional (artículo 201), la Defensoría del Pueblo (artículo 161), Ministerio Público (artículo 158), Ex Consejo Nacional de la Magistratura y hoy Junta Nacional de Justicia (artículo 150), conforme a la Ley N³0904, Ley de Reforma Constitucional sobre la conformación y funciones de la Junta Nacional de Justicia (publicada el 10 de enero del 2019), Jurado Nacional de Elecciones (artículo 177), Oficina Nacional de Procesos Electorales (artículo 177), Registro Nacional de Identidad (artículo 177), Banco Central de Reserva (artículo 84), Superintendencia de Banca, Seguros y Administradoras Privadas de Fondos y Pensiones (artículo 87), Contraloría General de la República (artículo 82).

A través de su desarrollo jurisprudencial, el Tribunal Constitucional peruano, ha emitido diversos fallos que ponen en evidencia las tensiones generadas en cumplimiento de las atribuciones de éstos organismos, muchas de ellas han merecido críticas importantes que incluso generaron pronunciamientos contradictorios entre los integrantes de este colegiado.

\section{EL CONTROL SOBRE EL TRIBUNAL CONSTITUCIONAL:}

Si consideramos al Tribunal Constitucional como parte del esquema constitucional de división de poderes, una de las cuestiones más complejas a dilucidar, versa sobre la posibilidad de su control; que si bien no viene expresamente contemplada por la Constitución que constituye su norma fundante, no significa tampoco que tenga atribuciones (de control e interpretación constitucional) ilimitadas, a decir de César Landa (2011), pues a pesar de no haberse establecido un control en específico para el controlador, en opinión de Carpizo (2009) existen controles meta constitucionales que se dirigen a dicho objetivo, tales como :

\subsection{El control indirecto que ejercen los órganos supranacionales:}

Este tipo de control si tiene sustento legal en el artículo 114 del Código Procesal Constitucional, sin embargo se encuentra condicionado a que el país acepte la competencia jurisdiccional de los tribunales supranacionales como la Corte Europea de Derechos Humanos o la Corte Interamericana de Derechos Humanos, las cuales nacen de las convenciones suscritas para la protección de los derechos fundamentales; este control se hace efectivo una vez agotadas las instancias internas; sin embargo, sus efectos no recaen directamente sobre el Tribunal, sino que responsabilizan al Estado por violación de los derechos garantizados en las convenciones a las que deben su origen.

Esta suerte de control supranacional también ha sido identificado con el "control de convencionalidad" instituido por la Corte Interamericana de Derechos Humanos, que a lo largo de su desarrollo jurisprudencial (Caso Myrna Mack Chang vs Guatemala, caso Tibi vs Ecuador, caso López Álvarez vs Honduras, caso Almonacid Arellano vs Chile, caso de los trabajadores cesados del Congreso peruano, caso Fernández Ortega vs México y caso Masacres de Río Negro vs. Guatemala) 
ha sentado las bases para que los jueces ordinarios tengan el poder de abstenerse de aplicar cualquier norma (o interpretación de la misma) que colisione con los postulados de la Convención Americana de Derechos Humanos o con la interpretación que de ellas haya realizado la Corte Interamericana, incluso cuando dicha contradicción provenga de la interpretación de la propia constitución.

Néstor Pedro Sagúes (2009), al respecto distingue el control de convencionalidad del control de constitucionalidad por los objetivos que persiguen, el primero intentando afirmar la supremacía del Pacto de San José de Costa Rica, mientras que el segundo la supremacía de la constitución nacional; por ello en el supuesto de oposición de una norma constitucional con la Convención Americana, el Estado debe cumplir con la Convención a todo costo y no puede alegar su constitución para incumplirla, asumiendo dicha Convención una condición de supra constitucionalidad. No cabe duda entonces que el control de convencionalidad es una atribución directa de los organismos supranacionales respecto de los fallos emitidos por el Tribunal Constitucional como órgano de cierre de interpretación constitucional en nuestro sistema jurídico, lo que no merece mayor análisis por ser expresión de un control concentrado previsto en la norma procesal constitucional; sin embargo, ello deja entrever que existe la posibilidad de ejercer un control difuso de convencionalidad, y si ello es así, genera la prerrogativa no solo al juez constitucional, sino al juez ordinario en general, a ejercer un control sobre las decisiones del propio Tribunal que contravengan los principios y garantías que contempla la Convención Americana.

Es recién a partir del caso Almonacid Arellano vs Chile que el Pleno de la Corte Interamericana de Derechos Humanos, por primera vez, reconoce la terminología de Control de Convencionalidad; y es Ferrer Mac-Gregor (2010) quien sostuvo que su connotación es más amplia pues tiene dos manifestaciones: una de carácter concentrada por parte de la Corte en sede internacional, y otra de carácter difusa para los jueces nacionales en sede interna, este criterio se advierte de su fundamento 124, en el que asevera que cuando un Estado ha ratificado un tratado internacional como la Convención Americana, sus jueces -como parte del aparato del Estado- también están sometidos a ella, lo que les obliga a velar porque los efectos de sus disposiciones no se vean mermadas por la aplicación de leyes contrarias a su objeto y fin y que desde un inicio carecen de efectos jurídicos. El poder judicial debe ejercer una especie de "control de convencionalidad" entre las normas jurídicas internas que aplican en los casos concretos y la Convención Americana, para lo cual debe tener en cuenta no solamente el tratado, sino también la interpretación que del mismo ha hecho la Corte Interamericana, como su intérprete última.

Pero esta facultad de control se extiende no solo a los órganos jurisdiccionales sino también a todos los órganos del Estado, así a partir del caso Fernández Ortega vs. México, la Corte Interamericana sostuvo que si bien el control de convencionalidad es un poderdeber de los jueces, éste se extiende a todos los órganos vinculados a la administración de justicia en todos los niveles como es el caso del Ministerio Público, organismos que es mencionado expresamente en la sentencia emitida en el caso Masacres de Río Negro vs. Guatemala, en la cual se agregó como parámetro de interpretación para los jueces y órganos vinculados a la administración de justicia a los demás instrumentos interamericanos y la interpretación que de éstos haya efectuado la Corte, lo que constituye el denominado "bloque de convencionalidad", entre los cuales tenemos a la Convención Interamericana para prevenir y sancionar la Tortura, la Convención Interamericana para Prevenir, Sancionar y Erradicar la violencia contra la Mujer (Belem do Pará) y la Convención Interamericana sobre Desaparición Forzada de Personas; posición que no es pacífica en la doctrina, pues para cierto sector, más que un control especial, se trata del mismo control de constitucionalidad en la que se incluye la interpretación conforme a los tratados de derechos humanos, ya que éstos han sido incorporados por disposición de la propia constitución, como norma interna a la cual se le otorga rango constitucional o eficacia directa.

Como quiera que se conciba este control (inaplicación de normas internas contrarias a la Convención), lo cierto es que éste debe ser limitado, pues constituye la última ratio a la que el juez interno debe acudir como método de control de las decisiones emitidas por el Tribunal Constitucional, así como también debe regularse internamente un procedimiento para su aplicación, a efecto de no contravenir competencias exclusivas de otros órganos o sistemas de control, máxime si se tiene en cuenta que la jurisdicción internacional es de carácter subsidiario, coadyuvante y complementario, no desempeñando funciones de tribunal de cuarta instancia.

\subsection{La facultad de análisis crítico de los ciudadanos respecto a las resoluciones judiciales (control ciudadano):}

El artículo 139 inciso 20 de la Constitución Política del Perú reconoce como un Principio de la Función Jurisdiccional la posibilidad de crítica a las resoluciones 
judiciales y sentencias emitidas por los órganos jurisdiccionales, con las limitaciones que establezca la ley; dicha prerrogativa se justifica con mayores argumentos cuando se trata de las sentencias que emite el Tribunal Constitucional, no sólo porque sus decisiones se someten al Poder Constituyente que lo creó, sino porque dada su condición de intérpretes privilegiados de la Constitución, sus decisiones están permanentemente sometidas al escrutinio público de juristas, políticos y público en general, estando siempre sometidas a debate público.(Brague,2006, 330-331) Carpizo (2009), justifica la existencia de este principio en el hecho de que las sentencias que emite este colegiado constitucional tienen connotaciones políticas, religiosas y económicas de gran trascendencia a nivel nacional, por ello sus decisiones además de ser de interés de quienes promueven los procesos constitucionales, suscitan el interés de los poderes públicos, partidos políticos, organizaciones sociales y de la sociedad civil en general, considerando en ocasiones que éstas responden a intereses particulares o grupales, - que detrás de ellas se evidencian preferencias políticas, ideológicas o religiosas de los magistrados que las emiten.

Somos claros en afirmar, en consonancia con la opinión vertida por Acuña (2014), que "este control no tiene los mismos efectos que el ejercido por los órganos jurisdiccionales (ordinarios o constitucionales) o supranacionales, pues éstas críticas no tienen carácter vinculante, aunque no se puede negar su influencia cuando la crítica es mediática" ( $p, 90)$, ejemplo de ello tenemos a la resolución anulatoria (EXP. N ${ }^{\circ} 00791$ 2014-PA/TC) emitida por el Tribunal Constitucional en el caso "Mateo Castañeda" (reseñado anteriormente), en la que un nuevo pleno (conformado por el actual Tribunal a excepción del magistrado Ferrero Costa), utilizando la figura procesal del recurso de reposición, dejó sin efecto la muy cuestionada sentencia emitida en octubre del 2013, por la cual se ordenaba a los integrantes del Ex Consejo Nacional de la Magistratura nombrar a Mateo Castañeda Segovia como Fiscal Supremo, argumentando violación del Principio de Cosa Juzgada y vulneración a las competencias constitucionales del CNM.

\subsection{Cuando el control lo ejercen los poderes sometidos a control (límites impuestos por el Presidente de la República y el Congreso):}

En un Estado Constitucional de Derecho, la Constitución ha previsto procedimientos para que los poderes constituidos como el ejecutivo, representado por el Presidente de la República, o el Poder Legislativo en uso de sus atribuciones constitucionales, puedan ejercer control sobre el Tribunal Constitucional; controlar al controlador no representa una opción contraria a la Constitución, sin embargo, a lo largo de la historia de nuestro Tribunal, así como de su más cercano antecedente, esto es el Tribunal de Garantías Constitucionales, los intereses políticos que motivaron su ejercicio, terminaron por deslegitimar dichas iniciativas.

Acuña (2014), plantea los siguientes supuestos en los que se ha ejercitado este control:

a) Modificación de la Constitución vía Ley de Reforma Constitucional para superar sentencia del Tribunal Constitucional, situación que se presentó con la dación de la Ley N²8642 que modificó el artículo 5 inciso 8 del Código Procesal Constitucional, regulando la improcedencia del amparo electoral, a pesar de haberse emitido con anterioridad la sentencia en el caso "Lizana Puelles" (Exp. N5854-2005- PA/TC) que interpretó su procedencia; sin embargo, esta ley fue declarada inconstitucional por el propio Tribunal a través de la STC N00007-2007-PI/TC (caso Colegio de Abogados del Callao).

b) La modificación de la estructura del Tribunal Constitucional, el número de su magistrados y su competencia, este tipo de intervención se verificó en nuestro país en dos ocasiones, la primera cuando el 05 de abril de 1992, el ex presidente Alberto Fujimori Fujimori, anuncia el cierre del Congreso de la República, así como la intervención del Poder Judicial y del Tribunal de Garantías Constitucionales, el mismo que se materializó a finales de junio de 1996, cuando se eligieron los nuevos magistrados del Tribunal Constitucional, pues durante cuatro años y tres meses, este Tribunal no pudo funcionar; el segundo ejemplo se presenta con la dación del Proyecto de Ley N¹4321/2005-CR propuesto por el ex congresista Antero Flores Aráoz, cuyo objeto era recortar las facultades del Tribunal Constitucional en materia de interpretación constitucional, eliminando de su Ley Orgánica su facultad como supremo intérprete de la Constitución, proyecto que nunca llegó a convertirse en ley

c) El control directo y personal a los miembros del Tribunal a través de un juicio por responsabilidad política, esto se presenta cuando se alega violación a la Constitución por parte de los magistrados del Tribunal Constitucional, lo que implica iniciar un procedimiento de acusación constitucional que se encuentra previsto en los artículos 99 y 100 de la Constitución Política. 
Este método de control generalmente ha sido utilizado erróneamente en nuestro país, como una forma de castigar la actitud de magistrados independientes, que a través de sus decisiones se enfrentan al poder político; así tenemos lo ocurrido en los años noventa con la destitución de tres magistrados del Tribunal Constitucional quienes fallaron en contra de la reelección del presidente Alberto Fujimori Fujimori, los mismos que haciendo uso del control difuso inaplicaron la ley que permitía su reelección; situación análoga se presentó recientemente con la acusación constitucional promovida contra cuatro de los actuales magistrados del Tribunal, Manuel Miranda Canales, Marianella Ledesma Narváez, Carlos Ramos Núñez y Eloy EspinosaSaldaña Barreda, alegando infracción a la Constitución, vulneración del Principio de Cosa Juzgada y la comisión de delito de prevaricato; ello tuvo lugar con motivo del pronunciamiento respecto de la subsanación de la sentencia emitida en el EXP. N. o 01969-2011-PHC/TC (a través de un auto de fecha 05 de abril del 2016), con el cual se resolvía un pedido de subsanación de error material en su emisión, relacionada con el denominado "Caso El Frontón" (data del año 2013); cargos que fueron negados por los denunciados, alegando amenazas a su independencia funcional por parte de la oposición fujimorista en el Congreso, por lo que acudieron a la Comisión Interamericana de Derechos Humanos y posteriormente a la Corte Interamericana, organismo internacional que resolvió se archive el procedimiento de acusación constitucional iniciado por el Congreso.

d) El control político en la designación de los miembros del Tribunal Constitucional, pues en nuestro sistema la elección de sus magistrados es de naturaleza política, en tanto las candidaturas son propuestas por los grupos parlamentarios, quienes también intervienen en su elección; ello en la práctica no constituye una garantía de imparcialidad, más aún cuando a lo largo de su historia se han visto casos de elecciones de miembros con afinidad al poder político.

Sin embargo, no podemos considerar a este último en estricto como un método de control del poder del Tribunal Constitucional, se trata más bien de medidas destinadas a obstaculizar o neutralizar sus funciones las cuales configuran un abuso de las atribuciones consagradas constitucionalmente al Poder Legislativo.

\subsection{El Tribunal Constitucional y su necesidad de autocontrol:}

Hasta este punto hemos advertido que la justicia constitucional, cuyo "intérprete privilegiado" es el Tribunal Constitucional, genera ciertos riesgos para el funcionamiento adecuado del sistema jurídico- político; así lo define Pérez (2003), tipificando estos riesgos de la siguiente manera:

“a.- El riesgo de politización que genera, dada la trascendencia y naturaleza de los asuntos que resuelve, más allá de que las soluciones se basan en interpretaciones del derecho de conformidad con la constitución que informa un determinado sistema jurídico.

b.- El riesgo de que a partir de esta politización de sus decisiones, genere un peligro de invasión a los ámbitos reservados tradicionalmente a los poderes del Estado (ejecutivo, legislativo y judicial).

c.- El riesgo que al ser un único tribunal que se encarga (de conformidad a sus atribuciones previstas en la Constitución) tanto al afianzamiento de los principios y valores constitucionales garantizando los derechos fundamentales de las personas, como también a la solución de los conflictos importantes para la vida del país, genere una sobrecarga laboral difícil de manejar". $(p, 9)$

En vista de ello, evitar que estos riesgos se conviertan en realidad, no solo depende del control externo que se imprima a este organismo constitucional, sino fundamentalmente al autocontrol de la justicia constitucional.

El autocontrol o "self restraint" se justifica especialmente en un Estado Democrático de Derecho, en el que por el juego de poderes, los órganos que se encuentran en la cúspide del poder, deben autocontrolarse, incluso así estén bien definidas sus atribuciones y se verifique realmente un equilibrio de poderes (checks and balances); el mejor ejemplo de ello es lo que sucede en la Suprema Corte de los Estados Unidos, quien se impone límites a sí misma como una manera de ajustarse a sus competencias sin afectar la de otros órganos del poder público. (Carpizo, 2009). Finalmente, Vanossi citado por Monroy (2004) ha expresado que:

“....nos encontramos frente a un problema análogo al de la cuadratura del círculo: o no hay control, y entonces podemos desembocar en la ilimitación del ejercicio de los poderes, que significa el quebrantamiento de las competencias y limitaciones establecidas por la Constitución; o establecemos el órgano de control, pero enseguida se plantea el problema de quién controla al controlador, al surgir el riesgo de que dicho órgano asuma una verdadera "dictadura" interpretativa de los textos constitucionales, y descalifique todos aquellos actos o normas que 
no se compadezcan con las valoraciones que él explicita. Como vemos, todos los caminos conducen a la interpretación; y la enorme importancia de esta queda en evidencia cuando percibimos que toda la función de control está finalmente subsumida en la tarea de interpretación que cumple el órgano especializado..." $(p, 24)$

\section{LA INTERPRETACION CONSTITUCIONAL Y EL ENFOQUE ADECUADO ENTRE EL ACTIVISMO Y EL AUTOCONTROL COMO RESPUESTA AL TOTALITARISMO DEL TRIBUNAL CONSTITUCIONAL}

Respecto al control del Tribunal Constitucional como órgano constitucionalmente autónomo, que debido a sus atribuciones cuenta con una cuota importante de poder dentro de un Estado Constitucional de Derecho; se han definido algunas formas de control externo (controles meta constitucionales en clara alusión a la propuesta de Carpizo), los que podrían ser catalogados como formales (en tanto tienen por finalidad verificar a partir de procedimientos regulados en la ley, el desempeño funcional y la función jurisdiccional de sus integrantes: magistrados del Tribunal Constitucional); sin embargo, a partir de las ideas expuestas, proponemos la necesaria observancia de un modelo de control material, que sin representar necesariamente un activismo extremo, optimice el objeto de la justicia constitucional, esto es el respeto a la Constitución, interpretándola a partir de los valores y principios incluidos en ella, a fin de determinar los márgenes o lineamientos que toda autoridad debe observar en el ejercicio de sus funciones a efecto de garantizar un marco de protección a los derechos fundamentales de los ciudadanos.

Considerando que lo que se propone es la aplicación de un modelo de control material o sustantivo, la primera interrogante que debemos satisfacer es ¿cuáles son los presupuestos de aquel modelo de control?, y fundamentalmente ¿cómo se hace efectivo dicho control?, para ello partimos de la función que durante los últimos años viene cobrando mayor reconocimiento en el sistema constitucional, esto es la interpretación de la Constitución no solo como norma política, sino fundamentalmente jurídica (ubicada en la cúspide de la pirámide kelseniana), sin dejar de lado la importancia de ésta en el reforzamiento del Estado Constitucional de Derecho, a partir de fijar las condiciones para funcionar en niveles óptimos en una democracia (Figueroa, 2017, $p, 639)$.

\subsection{El Totalitarismo en el Tribunal Constitucional:}

Considerando la importancia que representa el Tribunal Constitucional en el sistema de justicia constitucional, dadas sus competencias -algunas de ellas exclusivas y excluyentes- como la de ejercer el control concentrado de constitucionalidad, conocer en última y definitiva instancia las resoluciones denegatorias de hábeas corpus, amparo, hábeas data y cumplimiento, así como conocer los conflictos de competencia y atribuciones signadas por la Constitución a los distintos órganos del Estado; su ejercicio le genera una suerte de posición privilegiada que no pocos han criticado e incluso intentado limitar; sin embargo se hace necesario analizar si ese lugar predominante dentro del ordenamiento constitucional encuentra justificación dentro de un Sistema Democrático de Derechos, máxime si no es un secreto que está envestido de una "energía correctora" que no solo controla la actividad normativa del poder político, sino también los actos de poder (administrativos e incluso judiciales) y los actos particulares de los ciudadanos, en la medida que colisionan con los principios y valores que propugna la Constitución (contenido constitucionalmente protegido de los derechos fundamentales) (Castillo, 2008). Si ello es así, preguntémonos ¿de dónde proviene tal privilegio?, si es que ¿acaso no es fruto del Poder Constituido como lo son el Ejecutivo, el Legislativo, el Judicial, así como los demás órganos constitucionalmente autónomos?

La pregunta anterior encuentra respuesta en los aportes de Carpizo (2009), quien, tomando las ideas de Sieyés en Francia y Alejandro Hamilton en Estados Unidos, diferencia al Poder Constituyente del Poder Constituido; el primero (por ser originario) es el presupuesto del segundo, es el poder creador y por lo tanto ilimitado; a él le deben su origen no solo la Constitución, sino además el poder revisor de ésta y el Tribunal Constitucional, los poderes legislativo, ejecutivo y judicial y los órganos constitucionalmente autónomos.

Lo interesante de esta propuesta es que encuentra un nivel jerarquizado entre los poderes, dividiéndolos en constituidos primarios y secundarios, ubicando entre los primeros al Órgano Revisor de la Constitución y al Tribunal Constitucional; sin embargo no es muy claro en precisar cuál es el origen de dicha jerarquización, estableciendo solo un criterio funcional de diferenciación.

Entendemos que el poder revisor de la Constitución tiene una competencia especial, la cual no es sino modificarla, ello en buena cuenta significa variar la estructura, integración y funciones de los poderes destinados a dirigir los destinos de la sociedad; sin embargo, no todo es sujeto a modificación en la 
Constitución, criterio que es asumido por ejemplo a partir de la interpretación de constituciones como la americana (vigente desde del año 1787, luego de ser ratificada por los trece estados conformantes de la Confederación, actualmente cuenta con 27 enmiendas, la última de las cuales se produjo en el año 1992) (The U.S. National Archives and Records Administration 2019); pero que lamentablemente dista mucho del modelo adoptado en nuestra realidad latinoamericana y fundamentalmente nacional, ello se manifiesta pues desde el inicio de nuestra historia republicana, se han promulgado hasta 12 constituciones (y un estatuto provisional) (Ramos, 2018).

Conforme a aquella propuesta, el órgano revisor de la Constitución, puede crear incluso a los órganos constitucionales autónomos, y si bien el Tribunal Constitucional se estructura como uno de ellos en la mayoría de ordenamientos constitucionales que lo contemplan, su naturaleza es superior en atención a las atribuciones que le han sido asignadas; en tanto está facultado para controlar la constitucionalidad de las normas y actos que ellos emiten, y siguiendo una lógica fundamental, no podrá ejercer esta función si no gozara de superioridad; por lo que más allá de los conflictos o tensiones que pudieran originarse entre los poderes constituidos secundarios (los que serán tratados como conflictos de competencia), las decisiones del Tribunal Constitucional estarían por encima de los demás órganos; ello no quiere decir de ningún modo, que sus facultades sean ilimitadas, pues al ser ambos producto del poder constituido, sus funciones se encuentran demarcadas en la propia Constitución, por ello es que llegamos a la conclusión de que el Tribunal Constitucional tiene un límite preciso: la Constitución; ello se sustenta en que la idea central de un sistema democrático de gobierno es la autocontención de sus poderes (checks and balances), lo que hace necesario incluso que el poder del controlador sea responsable y también sujeto potencialmente al control.

El funcionamiento del Tribunal Constitucional peruano, creemos, se sustenta en aquella postura, la cual se materializa en lo previsto en el artículo $14^{\circ}$ de su Ley Orgánica, que señala: "Los magistrados del Tribunal Constitucional no están sujetos a mandato imperativo ni reciben instrucciones de ninguna autoridad. Gozan de inviolabilidad. No responden por los votos $u$ opiniones emitidas en el ejercicio de su cargo..."; esto no implica falta de responsabilidad en sus decisiones, por el contrario, comporta un legítimo interés en bien del Estado y de la propia jurisdicción constitucional, así, aun gozando de independencia, el Tribunal Constitucional está sometido a las reglas de la Constitución.
Entonces, la independencia funcional e institucional es respecto a los demás órganos del Estado, puesto que el Tribunal Constitucional es un poder sui generis que va más allá de lo político y jurídico; en realidad va al encuentro de la razón y la coherencia entre el derecho y la justicia.

Coincidimos con Castillo (2008) en que en nuestro orden constitucional no se ha previsto expresamente, por un lado, que ningún órgano cumpla la labor contralora directa sobre el Tribunal Constitucional; y ello es así, porque (al menos en la idea del Poder Constituyente que dio origen a la actual Constitución Política) dicho tribunal fue concebido como un órgano privilegiado $(p, 65)$.

Por ello, dado el poder que se le ha atribuido en el sistema peruano, debe asumir una posición de autocontención, tratando de evitar la concentración del poder en la mayoría o totalidad de sus miembros, lo que se consigue a partir de un enfoque interpretativo de la Constitución.

\subsection{La interpretación constitucional y su enfoque en la postura propuesta}

A través de la interpretación los Tribunales realizan un enjuiciamiento de las facultades de los poderes públicos (y eventualmente de las actuaciones privadas) a la luz de la norma constitucional, por lo que consecuentemente sus decisiones tendrán repercusiones directa o indirectamente en el ciudadano como sujeto de derechos fundamentales.

Por ello, una preocupación constante en los magistrados del Tribunal Constitucional, a pesar de su herencia kelseniana (empeñándose aún por separar los problemas de legalidad y de constitucionalidad), ha sido la de evitar en lo posible sustituir al Parlamento, verificando si la aplicación de una determinada norma, se adecua al texto constitucional; por ello no cabe duda que el juez constitucional no limita su actuación únicamente al control formal de constitucionalidad, sino fundamentalmente a ejercer un control sustantivo, pero ello conlleva intrínsecamente una suerte de esfuerzo "auto inhibitorio" a fin de no invadir atribuciones del legislador positivo (Gascón, 1994, p, 68).

Siendo así, el objeto de interpretación principal del Tribunal Constitucional traspasa la frontera de la ley, pues está dirigido fundamentalmente a extraer el sentido de la norma constitucional cuyo fin es la defensa de la persona humana y el respeto de su dignidad (artículo uno de la Constitución peruana), para lo cual lleva a cabo una argumentación finalista; por ello, en nuestro esquema de justicia constitucional, los fundamentos de sus sentencias representan una 
especie de legislación, especialmente cuando expresamente prescriben su carácter vinculante (precedente vinculante) o como doctrina jurisprudencial, situaciones en las que no solo se comporta como un verdadero juez (interpreta y argumenta) sino también dicta sentencias con fuerza de ley.

La importancia de la interpretación en un Estado Constitucional y Democrático de Derecho radica en que los ejecutores de ésta (los magistrados constitucionales) son los destinatarios de la confianza de la comunidad, en tanto ejercen la delicada labor de impartir justicia en base a un deber de motivar que constituye uno de los fundamentos esenciales de todo estado; existe por tanto una relación directa entre la función judicial (constitucional) y la realización de un acto de justicia mediante la interpretación.

La interpretación a la que nos referimos, sin duda alguna, se trata de una interpretación especial, pues como lo expresara en su oportunidad (García, 2005), la interpretación está condicionada por el tipo de norma a la que debe aplicarse y la de carácter constitucional posee aspectos singulares significativos que requieren de principios peculiares que no se aplican a otros tipos de preceptos jurídicos, los que no se refieren a la actividad interpretativa como tal, sino al tipo de normas a las cuales se aplica y a los sujetos que deben interpretarlas.

Debemos tener en cuenta que la determinación del contenido de las normas constitucionales no es una tarea sencilla, pues además de los preceptos referidos a los derechos fundamentales (parte dogmática, integrada también por principios y valores superiores), y las que regulan la organización y funcionamiento de los diversos órganos del poder (parte orgánica), también contienen disposiciones de carácter reglamentario que la dotan de un contenido jurídico y no solo político; su complejidad además viene dada, a partir de su estructura, pues constituye el fundamento de validez de todo el ordenamiento jurídico; por ello es que se entiende que ningún precepto jurídico de inferior jerarquía debe ser contrario a sus disposiciones. Es una interpretación muy vinculada con la axiología, pues el intérprete debe realizar una actividad muy compleja, basada no únicamente en los principios de la lógica formal y material, sino también conforme a los principios básicos de la argumentación máxime si (conforme a lo anteriormente anotado) existe la obligación de justificar los resultados de la misma (FixZamudio, 2005).

Según Fix- Zamudio (2005), se debe distinguir además entre la interpretación judicial de la Constitución que realizan los jueces ordinarios y la que efectúan los tribunales constitucionales, aun cuando éstos últimos no tengan la exclusividad de la misma pero si una postura privilegiada sobre ella, en tanto su función primordial es realizar una interpretación final (de cierre) de la norma fundamental en un Estado Constitucional de Derecho; distinción que se justifica en el hecho de el punto de referencia para la judicatura ordinaria son las disposiciones legislativas interpretadas, mientras que los Tribunales Constitucionales tienen su referencia inmediata en la Ley Suprema; y si bien ambas jurisdicciones realizan una doble interpretación de la ley y de la Constitución, los jueces ordinarios lo hacen desde la primera y los constitucionales respecto de la segunda; además los jueces ordinarios se encuentran subordinados a la interpretación privilegiada y obligatoria que realizan los jueces constitucionales (Tribunal Constitucional), situación que se verifica incluso en el sistema de control difuso, en el que los jueces de cualquier categoría están obligados a inaplicar las normas contrarias a la Constitución, pero acorde al principio del stare decisis, están obligados a seguir la interpretación que el Tribunal Constitucional (Corte Constitucional o Corte Suprema) haya realizado, luego de determinar la constitucionalidad de la disposición legislativa en cuestión.

\subsection{Importancia de la interpretación constitucional en la limitación de las atribuciones y facultades del Tribunal Constitucional}

Si partimos de la idea expuesta por Carpizo, en relación a que los Tribunales Constitucionales como Poder Constituido Primario, no gozan de facultades ni atribuciones ilimitadas en el ejercicio de sus funciones, y cuyo límite - entonces- responde a la propia Constitución Política a la que deben su origen, no pueden escapar al principio constitutivo de todo orden político, en virtud del cual existen reglas cuyo acatamiento les permite auto limitarse.

Así surgen dos concepciones que tienen su origen en la Suprema Corte Federal de los Estados Unidos (tendencias): el auto control judicial o también llamado Self Restraint, corriente a través del cual se impone límites a sí misma, a efectos de ajustar sus competencias sin afectar a la de otros órganos del poder político; y el activismo judicial, o también llamado Judicial Activism, a partir del cual se busca lograr una protección efectiva a los derechos fundamentales, teniendo en consideración la naturaleza "viva" de la Constitución.

Consideramos que los objetivos en la aplicación de ambas tendencias no se encuentran tan alejados entre sí, puesto que en ambos casos se pretende una interpretación de la norma fundamental de 
conformidad a su fin último y más esencial, como lo es el respeto a la dignidad de la persona como fin supremo del Estado; creemos también en la necesidad de justificar la adopción de la tendencia del activismo judicial de acuerdo a las condiciones institucionales de cada estado, lo que quizás ayudará a estructurar un sistema constitucional de transición de un país en vía de desarrollo, hacia otro con diseño de políticas democráticas que permitan el establecimiento de una cultura constitucional y un sistema de partidos políticos sólidos que permitan la consecución del objetivo anteriormente expuesto.

\subsubsection{El autocontrol judicial}

Modelo identificado originalmente bajo la denominación de judicial restraint, y que propugna básicamente que un juez no puede modificar la ley o la Constitución ni crear nuevos derechos constitucionales con el riesgo de caer en un subjetivismo; su aplicación se basa en un método originalista de interpretación (original understanding) que tiene como objeto encontrar la justificación última de la justicia constitucional conectándose con el pensamiento del constituyente originario, reduciéndose así la facultad de control constitucional de la Corte hacia los poderes públicos o privados; éste posición se basa en el respeto a la voluntad de las mayorías a gobernar y así conciliar la judicial review con el ideal democrático que se sustenta en la idea que tuvieron los fundadores de la Constitución Norteamericana (frammes) acerca de la función social de la Constitución en bloque (Tribe, 2010).

Es una posición construida contra el activismo judicial predominante durante la presidencia de la Corte Suprema Norteamericana a cargo de Juez Warren (Corte Warren 1953-1969), reconocida porque durante aquella época se dictaron sentencias como Brown I que finalizó con la discriminación racial en escuelas y universidades, New York Times VS Sullivan que otorgó prevalencia a la libertad de expresión, Reynolds VS Sims referido a la delimitación de distritos electorales en los cuales se afectaba la representación de ciertas colectividades, entre otras (Arias, 2013, p, 255-256).

La discusión, como es notorio, se decanta en una postura restrictiva que se presenta en franca oposición a otra activista (ésta última considera la necesidad de ir actualizando el texto constitucional mediante su interpretación, a través de sentencias neutrales que expresen el significado de lo que la constitución "dice", sin juzgar lo que ella "debería decir"), tal y como lo expresa Berger citado por Beltrán (1989) “...la Constitución representa elecciones fundamentales ya hechas por el pueblo, y la tarea de los Tribunales consiste en hacerlas efectivas, no en construir nuevos derechos..." (p, 45). Ello se explica desde una lógica contractual rousoneana, asumiendo a la Constitución como una especie de contrato, que a diferencia de un estatuto, solo puede cambiar con el consentimiento de las partes, es decir que los cambios requeridos por la sociedad solo pueden materializarse con el consentimiento unánime y no solo con una mera preferencia mayoritaria (Posner, 1998, p, 577-580).

Por ello el juez Richard Posner se atrevía a afirmar que si la Corte Suprema interpretaba con mayor amplitud las disposiciones constitucionales que restringen las facultades de los poderes elegidos, lo que conseguiría es mover a la nación hacia un modelo de gobierno limitado, en el que la Corte se irroga el lugar del pueblo para limitar al gobierno; lo contrario, esto es si la Corte interpreta con mayor rigidez estas disposiciones, moverá a la nación hacia un verdadero gobierno democrático, el cual es más congruente con la posición de quienes representa y que carecen de poder político. En esa misma línea, Bork citado por Arias (2013) planteaba que ante una situación jurídica no desarrollada por el poder constituyente, no correspondía que el judicial - debe entenderse el órgano encargado de interpretar en última instancia a la Constitución- emita algún pronunciamiento, pues ello sería motivado por móviles subjetivos; por lo que ante el silencio constitucional corresponde que sea el órgano legislativo como representante del pueblo y haciendo uso del proceso democrático previsto por la Constitución, quien se encargue de desarrollarla, posición que se trasluce en lo que los juristas americanos denominaron strict constructionism. $(p$, 256).

Precisamente donde se aprecia la dicotomía entre ambas posturas, es en la resolución de los denominados casos difíciles (hard cases), en los que conforme a esta posición no sería válido argumentar una sentencia en los principios y valores constitucionales actuales, por tanto el conflicto debía ser siempre resuelto por el legislador positivo, sin duda alguna una posición extremadamente conservadora.

\subsubsection{La Interpretación constitucional sobre los "casos difíciles"}

Entendida la interpretación como una actividad parcialmente creativa, que se dirige a determinar el significado de algún aspecto relevante que no es claro o es indeterminado, por ende cuando interpretamos, siempre añadimos algo nuevo a aquello que se interpreta, interpretar la ley no escapa a dicha afirmación, incluso cuando quien desarrolla esta labor son los órganos jurisdiccionales, por eso en nuestro 
sistema jurídico, se concibe a la jurisprudencia (interpretación que hacen los jueces de la ley a la luz de un caso en concreto) como fuente de derecho; lo que nos lleva a una segunda conclusión, esto es, que para interpretar válidamente una ley, debe existir previamente un derecho que reconozca esa facultad.

En clave positivista, entonces, se entiende la distinción entre algunos casos en los cuales no se necesita de un método interpretativo (creativo), sino netamente lógico subjuntivo, esto es aplicar pura y simplemente el derecho (casos fáciles); mientras que en otros, cuyo margen de solución no está determinado por los estándares jurídicos que componen el ordenamiento, requieren de una labor creativa (casos difíciles); sin embargo, el análisis no puede agotarse en aquella definición, pues es sabido que incluso la subsunción requiere de un método interpretativo (literal), por lo que la diferencia entonces radica en la justificación que asume el intérprete sobre las decisiones a tomar, cuya intensidad difiere según se trate de uno u otro tipo de caso; ello en la actualidad es objeto de análisis por una -no tan reciente- disciplina jurídica que justifica el cumplimiento de los principios de toda labor jurisdiccional, es decir, el derecho- deber de la debida motivación de las resoluciones judiciales, denominada Teoría de la Argumentación Jurídica (TAJ).

Con base en lo expuesto, coincidimos con el maestro Atienza en que - al menos en los denominados casos difíciles- la justificación de la decisión no debe constreñirse únicamente a un razonamiento deductivo, debiendo complementarse con criterios de "razón práctica" que se encuentran contenidos en principios como el de universalidad, coherencia, concordancia, consenso, etc.; los mismos que han servido de presupuestos para que el Tribunal Constitucional peruano, por ejemplo, haya esbozado principios de interpretación propiamente constitucionales en una de sus resoluciones más importantes que tiene la calidad de precedente vinculante (Caso Lizana Puelles).

Dworkin citado por Atienza (2005) le agrega un grado de complejidad al problema, cuando a través de su tesis afirma que tanto en los casos fáciles como en los difíciles, el juez no goza de discrecionalidad, pues solo existe una única respuesta correcta en ellos, por eso para él la distinción entre éstos y aquellos no es tan importante, pues en ambos, el juez, está obligado a darles una solución siguiendo un mismo método o técnica.

Existe una última calificación expuesta por Atienza, catalogando como casos trágicos, a aquellos que no tienen ninguna respuesta correcta y que plantean a los jueces el problema de qué camino tomar frente a un dilema, mucho más que solo decidir entre una serie de alternativas o como ejercer su discrecionalidad; puesto que en ellos la solución jurídica necesariamente implica el sacrificio de algún elemento esencial de un valor considerado como fundamental desde el punto de vista jurídico o moral; se trata de aquellos casos en los que la decisión más adecuada, no necesariamente será la más justa en términos distributivos, pues se va a situar por encima del equilibrio mínimo. Es por ello que al presentarse una contraposición entre principios y valores (dimensión justificante de las normas), la solución se encuentra mediante una operación de ponderación, en la que se sopesan las diversas exigencias para alcanzar un punto de equilibrio mínimo u óptimo.

A pesar de estar diferenciados por una suerte de criterio de intensidad, la distinción entre un caso difícil y uno trágico, resulta un tanto ambigua en la práctica; para entenderla recurrimos nuevamente a los postulados de Atienza, para quien cabe hablar de dos tipos de casos trágicos, o -mejor aún- dos situaciones trágicas en las que se sitúa un juez: a) cuando el ordenamiento jurídico le provee al menos de una solución correcta (de conformidad con los valores jurídicos que lo informan) pero que choca con su moral; y b) cuando el ordenamiento jurídico no le permite alcanzar ninguna solución correcta, por lo que en ambas situaciones el intérprete no podrá arribar a una decisión sin infringir el ordenamiento jurídico.

La solución a la primera situación se sustenta en una posición originalista (restrictiva) -haciendo referencia a la dicotomía planteada con anterioridad- pues, en sistemas jurídicos democráticos, el ordenamiento jurídico estará compuesto por normas que por definición serían justas y morales, circunstancias bajo las cuales el juez no puede contraponer sus opiniones (subjetivas) respecto de lo que es moral a la opinión (objetiva) de la mayoría; por lo que bajo dicho esquema se descartan los problemas de conciencia, no debiendo existir entonces ninguna tragedia al respecto; distinta será la posición frente a la segunda situación, en la que si el sistema no permite llegar a una respuesta correcta, ello no significa que la solución del caso sea imposible, tampoco que no se pueda decidir por aquella que representa el mal menor (solución que representa una posición activista), pues lo que representó una tragedia para el operador, puede servir como aliciente para cumplir con sus deberes como ciudadano, contribuyendo a modificar el mundo social a fin de disminuir la "tragedia" en el caso, sentido que representa la frase del juez HOLMES al precisar que "... la vida del derecho no ha sido lógica, sino experiencia..." (Atienza, 2005, p, 143). 
A manera de conclusión podemos expresar que asumir una posición conservadora (originalista) en la interpretación constitucional de los casos difíciles, se caracteriza por: 1) el respeto absoluto por el texto constitucional así como por la voluntad del constituyente original (histórico), lo contrario implicaría convertirse en un tribunal político, así lo expresa Scalia, Juez de la Corte Suprema de Justicia de los Estados Unidos (1986-2016); 2) el intérprete de la Constitución solo debe manejar principios neutrales, que no son otra cosa que los postulados de los padres fundadores (framers), sin añadir principios o fines del intérprete. 3) la interpretación de la constitución solo debe enmarcarse a lo contemplado por el constituyente histórico, efectivizando su mensaje sin la necesidad de añadir al texto derechos no reconocidos por aquel, utilizando para ello el uso de la lingüística, la historia y la antropología. 4) El juez constitucional no posee facultades discrecionales para realizar una interpretación, debiendo efectuar como única respuesta constitucional correcta a aquella que surja de la Constitución. 5) Si un tribunal al interpretar la norma, se aparta del original mensaje del constituyente, invade competencias constituyentes atentando contra la soberanía popular. 6) Al juez constitucional le corresponde aplicar la Constitución y no modificarla (Arias, 2013, p, 257-258).

Entendemos entonces que los originalistas parten de una visión estática de la Constitución, casi venerando la voluntad del constituyente original; pero la realidad social es dinámica, y si bien en su interpretación se pueden enfrentar intereses e ideologías contrapuestos, e incluso contradictorios, los Tribunales Constitucionales, en un contexto de globalización de la justicia constitucional, no deben constreñirse a ser solo "ejecutores" de la Constitución, pues su finalidad primordial es la defensa de la persona y el respeto de su dignidad.

El enfoque originalista representa fundamentalmente el control a la actividad del Tribunal Supremo de los Estados Unidos, esto es la de declarar la inconstitucionalidad de leyes emergentes de un órgano democrático como lo es el Congreso Norteamericano; el mismo que pretende hacer frente a un "activismo judicial" (judicial activism) que desplaza el protagonismo de un órgano legislativo hacia el órgano judicial (Tribunal Constitucional en nuestro sistema) afectando de este modo al sistema democrático sobre el que se estructura el Estado.

No cabe duda que este enfoque recae directamente en la tarea interpretativa de los órganos que componen el sistema de justicia constitucional, en especial de los jueces del Tribunal Constitucional como Poder
Constituido Primario, y su adopción depende de la idea de Constitución aceptada en la sociedad organizada bajo cualquier sistema democrático de derecho.

Consecuentemente, son fundamentalmente dos teorías las que explican la visión interpretativa de la Constitución: aquella que propone que en lugar de interpretar la Constitución basada en las preferencias políticas de un juez, debe atenderse al texto del documento y la intención original de los que la formularon; y la Teoría de la Constitución Viviente (living constitution) como aquella que la concibe como un texto flexible y de fácil modificación.

Siendo así, y con el objeto de justificar la "liberación" del intérprete de la constitución, para alejarse de la voluntad del constituyente originario, han surgido tendencias revolucionarias (board constructionis), que pretenden realizar una interpretación utilizando acepciones del presente, principalmente en lo que corresponde a los conceptos de igualdad, libertad, propiedad, seguridad, etc.; circunstancia sobre la cual Dworkin (citado en Arias 2013) presenta un método interesante de interpretación que consiste en diferenciar los "conceptos" de las "concepciones" constitucionales, describiendo a los primeros mediante nociones jurídicas indeterminadas (idea de la moral pública, la dignidad humana, la justicia, etc) las mismas que deben ser dotadas de contenido por las generaciones futuras de intérpretes; las segundas, en cambio, constituyen ideas ya fijadas por el constituyente histórico, que resultan inmutables; demuestra su argumento en relación a lo dispuesto para el sistema punitivo, indicando que habría un concepto si la Constitución prohibiese las penas crueles, y una concepción si prohibiese expresamente la pena de muerte.

Conforme a este método entonces, interpretar una living constitution justifica la necesidad de propender a una interpretación evolutiva, pero ello trae consigo otro dilema que ha sido planteado por Guastini, dependiendo del carácter flexible o inflexible de la constitución, haciendo alusión a la posibilidad de su revisión y modificación mediante leyes, que sin ser de su misma naturaleza, alteran su contenido; para él una constitución es flexible en general porque es absurdo concebir que sea absolutamente inmodificable, pues al contener un aspecto normativo (valor jurídico de la Constitución) debe adaptarse al cambio de las relaciones económicas, sociales y políticas, pues de no ser así la única forma de cambiarla sería recurriendo a medios ilegales como el uso de la fuerza condenando a los pueblos a enfrentarse en guerras civiles cada vez que sea necesario un cambio de modelo constitucional; un segundo argumento a favor de la flexibilidad, se explica 
afirmando que no existe ninguna distinción entre poder constituyente y poder legislativo, ya que es éste último quien expresa la voluntad general, es decir encarna la soberanía, por ende el Poder Legislativo incluye el poder de revisión de la Constitución (tesis contraria a la propuesta por Carpizo a la que se hizo referencia anteriormente).

Como conclusión podemos afirmar que la concepción de la Constitución que impera en nuestro sistema de justicia constitucional, es en parte distinta al enfoque del constitucionalismo norteamericano, cuyo desarrollo ha sido producto de las distintas posiciones adoptadas por la Corte suprema Norteamericana en distintos periodos, que van desde una posición conservadora y originalista (autocontrol) hacia una tendencia innovadora y liberal (activismo judicial)

\subsubsection{El activismo judicial y la interpretación de los derechos fundamentales}

Lo expresado hasta este punto nos deja en claro que a través de la interpretación los Tribunales Constitucionales (Cortes Supremas o Cortes Constitucionales) adaptan la constitución formal (texto) a la constitución real (la realidad); ello sin tener que recurrir a efectuar reformas constitucionales permanentes; esto funciona siempre y cuando de la norma constitucional (a pesar de conservar su mismo texto) pueda extraerse significados diferentes, a través de los cuales el órgano contralor de ella (Tribunal) logre dicho objetivo.

Ahora, cierto es también que la Constitución como expresión del Poder Constituyente tiene sus propios límites expresados en los derechos humanos reconocidos como principios de ius cogens, los que por ende, constituyen límites infranqueables a la interpretación constitucional, considerando que donde el constituyente se vio impedido de legislar sin desnaturalizarse la Constitución, tampoco podría hacerlo el órgano de control de la constitucionalidad (Arias, 2013, p, 261).

Pero, si la Constitución requiere ser interpretada, ¿necesariamente dicha interpretación debe tomar en cuenta el significado que el texto tenía en el momento de su elaboración o la que tiene al tiempo de su aplicación?, esta postura cambiaría si considerásemos que el constituyente, consciente de sus limitaciones para prever los cambios sociales, económicos, culturales, etc. futuros, dejó un alto margen de apreciación al intérprete máximo de la Constitución, sin llegar a la desfiguración de la personalidad estatal. De este modo surge la postura del activismo judicial (judicial activism), que refleja la necesidad de que el juez constitucional tenga un papel activo en la interpretación de la Constitución, recurriendo a fuentes o valores no explícitos en ella, pero que emanan razonablemente de su contenido, cumpliendo a la vez un rol de creador del derecho, rompiendo con la rigidez del originalismo, postulando la independencia actual del texto original, de las valoraciones e intenciones del constituyente, interpretándola como un instrumento vivo, orgánico y cambiante (Sagüez, 2016, p, 27-28).

Esta postura tiene su fundamento ideológico de legitimidad en un argumento generacional, en relación a que cada generación tiene el derecho a vivir su constitución, pues la generación que la creó, no puede imponer a la generación actual su manera de entenderla; asimismo con el argumento del constituyente actual, que sostiene que la tarea de interpretar la Constitución no consiste en averiguar que quiso el constituyente histórico, sino en declarar la voluntad e intenciones de los actuales herederos y poseedores del poder soberano.

Como toda hipótesis jurídica está sujeta a crítica, la postura activista no se encuentra exenta de ella; sin embargo, reproducimos a modo de conclusión lo expuesto por SAGÜES (2016):

“...interpretar a la Constitución según las valoraciones sociales existentes, en las que haya un real y no meramente hipotético consenso unánime o cuasi unánime, no parece nada absurdo siempre que ese funcionamiento de la Constitución no violente a los derechos naturales de las personas y de las sociedades, ni afecte los compromisos internacionales del estado del caso..." $(p, 40)^{\prime \prime}$

\subsection{4. ¿Es posible asumir una posición ecléctica entre activismo y autocontrol?}

Para Figueroa (2017), el "activismo judicial", cuya naturaleza comprende una actitud de férrea defensa de los derechos fundamentales, responde a tres niveles de acción: activismo propiamente dicho, nivel más racional y razonable de defensa de los derechos fundamentales y del principio de primacía normativa de la Constitución; hiperactivismo, excesiva defensa de la justicia constitucional invadiendo competencia de otros órganos; e hipoactivismo, que representa la antítesis de la defensa de la Constitución, reflejando anomia de los órganos constitucionales y casi nula actuación de la justicia constitucional.

Para este autor, una muestra del primer nivel es la función desarrollada por la Corte Suprema Norteamericana bajo la presidencia del Juez Warren, periodo durante el cual registró un nivel importante de defensa de los derechos fundamentales; el segundo nivel, perjudicial a los fines de la justicia constitucional, 
ha originado sentencias que anulan decisiones del legislativo, del ejecutivo, e incluso sentencias del Poder Judicial; mientras que el último se instauró durante regímenes de facto o regímenes pseudo democráticos, en los que prevalece una situación de total desprotección de los derechos fundamentales.

Coincidimos con la posición del citado autor, en cuanto a que la interpretación activista se condice con una concepción "viva" de la Constitución, y su observancia cobra sentido especialmente en las condiciones institucionales de las democracias en desarrollo, las cuales cuentan con sistemas débiles de partidos políticos, contextos en los que muchas veces ha sido necesario que el Tribunal Constitucional actúe como sustituto del legislativo o vigilando al ejecutivo para garantizar la protección de los derechos fundamentales; sin embargo, esta posición no necesariamente tiene que estar desligada del self restraint, pues además de representar éste un ejercicio de autolimitación (necesario en todo Estado Constitucional de Derecho), creemos que resulta compatible con un activismo judicial restringido, pues implica la impartición de justicia constitucional dentro de los límites permitidos por la propia Constitución, constituyendo una dimensión material del activismo judicial (Figueroa, 2017, p, 618-619).

Entonces, definitivamente es necesaria la limitación a la función interpretativa del Tribunal Constitucional, a la que hemos denominado control sustancial o material para diferenciarla del control formal (al que nos hemos referido anteriormente), límite que es consustancial a una voluntad de autocontrol; y si bien el activismo judicial está justificado para garantizar efectivamente los derechos fundamentales de los ciudadanos, su aplicación no debe ser desmedida, no pretendiendo usurpar funciones atribuibles a otros órganos, salvo se verifiquen afectaciones graves a la Constitución, absteniéndose de crear posiciones filosóficas o morales (Carpizo, 2009).

Con base en lo expresado, pensamos en la necesidad de redefinir la posición del self restraint, considerándola como una tendencia en evolución, sucedánea al activismo judicial y que permite una interpretación óptima en las decisiones del Tribunal Constitucional, constituyendo una garantía de legitimidad para el ejercicio de funciones de control desde la Constitución sobre normas o actos vulneratorios de ella.

Esta nueva concepción del self restraint vendría caracterizada por: 1) Presuponer un principio de "justicia rogada", excluyendo la intervención de oficio, lo contrario puede encubrir una sobre actuación del Tribunal; 2) Un elevado estándar de motivación de las decisiones, dada la trascendencia que tienen las resoluciones emitidas por el Tribunal y el carácter vinculante de su interpretación como órgano de cierre del sistema constitucional interno, siendo cuidadosos de no usurpar el Poder Constituyente, evitando crear normas y principios que no sean susceptibles de reconducirse a la Ley Fundamental; 3) Reconocimiento de la especialidad constitucional, a fin de designar magistrados que desde su experiencia constitucional aporten a la solución de los conflictos entre derechos fundamentales, debiendo privilegiarse su versación en materia constitucional antes que otros criterios en su designación, que por su naturaleza es política en nuestro país; 4) Un plazo prudencial en el ejercicio de sus funciones, ya que existe una relación de causalidad entre la eficacia de un Tribunal y el plazo de duración del cargo de sus magistrados, el mismo que no debería ser tan reducido, lo que les permitirá afianzarse en el desempeño de sus cargos, en tanto el plazo de cinco años dispuesto en nuestra legislación se estima demasiado corto, pudiendo tomar como referencia el plazo previsto para los magistrados del Tribunal Constitucional español equivalente a 9 años; 5) Garantizar sistemas óptimos de elección, proponiendo que ésta no sea de cargo exclusivo del Parlamento, pudiendo considerar el sistema de cuotas español que involucra a otros poderes u órganos del Estado para la formulación de propuestas; 6) Que se garantice independencia de criterio, para lo cual el Parlamento debe verse impedido de formular acusaciones de orden constitucional por materias que competen a las funciones de los magistrados, reduciéndose solo para aquellas faltas graves debidamente comprobadas, lo contrario implicará sancionar al magistrado por expresar su posición, solo así se garantiza su legitimidad, cuando a su vez se garantice también mayor independencia de funciones; 7) Desarrollar una función pedagógica, que se materialice a través de la publicitación de todas sus resoluciones, lo cual además constituye una manifestación de transparencia que motiva la práctica del autocontrol, desde que si la voluntad del Tribunal es enseñar a través de sus decisiones, éstos debería seguir una misma línea jurisprudencial y solo variarla en situaciones estrictamente necesarias y a fin de optimizar la protección de los derechos fundamentales de los ciudadanos, constituyendo así sus decisiones un soporte de mejor predictibilidad y uniformización del Derecho Constitucional, máxime si por su propia naturaleza, constituyen referente y guía para la interpretación constitucional; 8) Considerando que la protección de los derechos fundamentales se enmarca dentro de un sistema regulado por normas convencionales (Tratados de Derechos Humanos), 
principalmente, los magistrados del Tribunal Constitucional deben promover un Espíritu de Convencionalidad, pues es obligación del juez constitucional observar los estándares fijados en la región por la Corte Interamericana de Derechos Humanos, adaptando sus decisiones al ámbito de convencionalidad que ésta fija; solo así sus decisiones adquieren verdadera legitimidad al respetar y observar los principios de legalidad, constitucionalidad y convencionalidad; 9) Desarrollar una interpretación activista de acuerdo con el contexto social y político en el que se desenvuelve la sociedad, considerando e identificando los valores democráticos que permitan el desarrollo equilibrado del poder, priorizando, sin embargo, una interpretación no subjetivista, neutral y prudente que priorice la seguridad jurídica, mediante el uso estrictamente necesario de los precedentes judiciales, cuya vinculación deberá respetar precisamente el propio Tribunal, garantizando su vigencia y aplicación en el tiempo; 10) Garantizar el respeto al contenido de una cláusula pétrea en la Constitución, porque su modificación injustificada estaría destruyendo la propia Constitución que lo creó, pues lo puede hacer solo el Poder Constituyente; 11) No se puede interpretar activamente la Constitución cuando el conflicto gire en torno a los principios y valores fundamentales que la individualizan aunque no estén expresamente detallados. 12). Se justifica la interpretación activista en la medida en que las condiciones institucionales de una sociedad no permitan un verdadero ejercicio de balance de poderes (check and balance), posición que viene asumiendo - a diferencia del colegiado anterior- la actual conformación del Tribunal constitucional peruano quien ha sostenido una posición moderada desde este enfoque interpretativo.

Finalmente es ineludible la responsabilidad que asumen los magistrados del Tribunal Constitucional en cumplimiento de sus atribuciones por lo que, al sistema constitucional le corresponde garantizar que éstos sean realmente independientes, legitimando su posición en un Estado Constitucional de Derecho, premisa que podrá hacer mucho más eficaz el funcionamiento de cualquier modelo de jurisdicción constitucional; y que a pesar de las diversas críticas a muchas de sus decisiones e intentos por recortar sus competencias, evidencian la necesidad de mantener su funcionamiento como agente de cambio en la sociedad.

\section{Conclusiones}

Los Tribunales Constitucionales creados como tales, o eventualmente los organismos que cumplen esa finalidad (Corte Suprema o Cortes Constitucionales) según el sistema de jurisdicción constitucional en el que se ubican, tienen en esencia las funciones de control constitucional de las leyes (abstracto o en concreto), resolución de conflictos constitucionales, de atribuciones y competencias, y protección de los derechos fundamentales

El Tribunal Constitucional peruano es un órgano autónomo e independiente que desempeña funciones constitucionales y jurisdiccionales, cuya organización, composición y estructura es regulada por la Constitución vigente y su Ley Orgánica y conforme a lo previsto por el artículo 202 de la Constitución, sus competencias pueden clasificarse en: competencias exclusivas (conoce los procesos de inconstitucionalidad y los procesos referidos al conflicto de competencias y/o atribuciones), competencias compartidas (con el Poder Judicial el ejercicio del control difuso de las normas legales, así como en el control difuso de convencionalidad y la protección de los derechos fundamentales de los ciudadanos en los procesos de tutela de derechos como el habeas corpus, el amparo, el habeas data y el de cumplimiento, pues conoce en última instancia el denominado recurso de agravio constitucional (RAC), luego de emitido el pronunciamiento en primera y segunda instancia) y competencias no previstas (control de las omisiones legislativas, el control de constitucionalidad de las normas infralegales, el control de los decretos que declaran estado de excepción, por ejemplo)

Debemos reconocer que gran parte de las instituciones procesales (que rigen el trámite de los procesos constitucionales), así como el desarrollo del contenido de los derechos fundamentales reconocidos por la Constitución, han sido producto de las decisiones emitidas (ya sea con carácter de precedente vinculante o de doctrina jurisprudencial) por el Tribunal Constitucional en los procesos que son de su competencia; sin embargo, muchas de éstas decisiones emitidas durante las distintas conformaciones de este colegiado han causado tensiones entre los distintos órganos que conforman la estructura del Estado, generando profunda crítica y cuestionamientos; pero no por ello podemos definirlas totalmente como buenas - malas, pues cuentan con aspectos positivos y negativos, o incluso en muchos casos los aspectos cuestionables fueron agregados a las sentencias luego de desarrollos jurisprudenciales positivos o acertados.

En nuestro orden constitucional no se ha previsto, que ningún órgano cumpla la labor contralora directa sobre el Tribunal Constitucional; y ello es así, porque (al menos en la idea del Poder Constituyente que dio origen a la actual Constitución Política) dicho tribunal 
fue concebido como un órgano privilegiado, aunque también se encuentra sujeto a algunas formas de control externo, debiendo considerarse también la necesaria observancia de un modelo de control material, que sin representar necesariamente un activismo extremo, optimice el objeto de la justicia constitucional, esto es el respeto a la Constitución, interpretándola a partir de los valores y principios incluidos en ella, atendiendo a su fin último en la defensa de la persona humana y el respeto de su dignidad.

Por ello debe el Tribunal Constitucional debe propender a una interpretación "restrictiva" de la Constitución pero redefinida como un atendencia sucedánea al "activismo judicial", la misma que cobra sentido especialmente en las condiciones institucionales de las democracias en desarrollo, que cuentan con sistemas débiles de partidos políticos; pues además de representar éste un ejercicio de autolimitación, expresa un activismo judicial restringido, que implica la impartición de justicia constitucional dentro de los límites permitidos por la propia Constitución.

\section{Bibliografía}

ABAD YUPANQUI, Samuel D. (2016). Constitución y Procesos Constitucionales. Lima, Perú: Editorial Palestra. Cuarta Edición actualizada.

ACUÑA CHAVEZ, Araceli (2014). Funciones y Competencias del Tribunal Constitucional Peruano. (Tesis para optar el grado académico de Magister en Derecho con mención en Derecho Constitucional). Pontificia Universidad Católica del Perú, Escuela de Graduados, Lima.

ARIAS LOPEZ, Boris Wilson (2013). "Rigidez e interpretación constitucional". En Pensamiento Constitucional. Volumen 18. Biblioteca Virtual PUCP. Consulta: 10 de marzo del 2019. Recuperado de https:// file:///C:/Users/USSER/Downloads/8957-355031-PB\%20(2).pdf

ATIENZA, Manuel (2005). "Los Límites de la Interpretación Constitucional” En: Interpretación Constitucional. Eduardo Ferrer Mac Gregor (Coordinador). Tomo I. México: Editorial Porrúa. BELTRAN, Miguel (1989). "Originalismo e Interpretación. Dworkin vs. Bork: una polémica constitucional". Madrid, España: Editorial Civitas

BRAGUE CAMAZANO, Joaquín (2006). "Interpretación Constitucional". En Revista Cuestiones Constitucionales. Volúmen №14. Perú
CARPIZO MACGREGOR, Jorge (1995). "Reformas Constitucionales al Poder Judicial Federal y a la jurisdicción constitucional del 31 de diciembre de 1994". En: Boletín Mexicano de Derecho Comparado - Nueva Serie. Año XVIII, N 83, mayo/agosto. México: UNAM.

CARPIZO MACGREGOR, Jorge (2009). El Tribunal Constitucional y sus límites. Lima, Perú: Editorial Jurídica Grijley.

CARPIZO MACGREGOR, Jorge (2010). "Discurso pronunciado por el doctor Jorge Carpizo en la ceremonia de inauguración del $\mathrm{X}$ Congreso Iberoamericano de Derecho Constitucional en su calidad de Presidente del Instituto Iberoamericano de Derecho Constitucional y del Comité Organizador del $X$ Congreso Iberoamericano de Derecho Constitucional". En Pensamiento Constitucional, Revista de la Escuela de Graduados de la Pontificia Universidad Católica del Perú. Año XIV, Número 14. Lima: Fondo Editorial de la PUCP.

CASTILLO CÓRDOVA, Luis (2008). El Tribunal Constitucional y su dinámica jurisprudencial. Lima, Perú: Editorial Palestra.

ETO CRUZ, Gerardo (2011). El desarrollo del Derecho Procesal Constitucional a partir de la jurisprudencia del Tribunal Constitucional peruano. Lima, Perú: Editorial Adrus. Cuarta edición.

FERNÁNDEZ SEGADO, Francisco (2001). "Derecho Procesal Constitucional." En FERRER MACGREGOR, Eduardo. Derecho Procesal Constitucional. Tomo I. México: Editorial Porrúa. Quinta Edición.

FERNÁNDEZ SEGADO, Francisco (2001). “La Jurisdicción Constitucional en América Latina. Evolución y problemática desde la independencia hasta 1979." En FERRER MAC-GREGOR, Eduardo. En Derecho Procesal Constitucional. Tomo I. México: Editorial Porrúa. Quinta Edición.

FIGUEROA GUTARRA, Edwin (2017). "Tribunal constitucional y self restraint.". En Retos del Constitucionalismo del Siglo XXI" - Ponencias del XI Congreso Nacional de Derecho Constitucional. Tomo I. Lima, Perú: Editorial Adrus

FIX-ZAMUDIO, Héctor (2005). "Lineamientos esenciales de la interpretación constitucional" En: Eduardo Ferrer Mac Gregor (Coordinador) Interpretación Constitucional. Tomo I. México: Editorial Porrúa

GARCÍA BELAUNDE, Domingo (1988). "El funcionamiento del Tribunal de Garantías Constitucionales". Fundación Friedrich Naumann. Enfoques peruanos temas 
latinoamericanos N06: El Tribunal de Garantías Constitucionales en debate. Lima

GARCÍA BELAUNDE, Domingo (1989). "El control de la constitucionalidad de las leyes en el Perú". En Jus Et Praxis: Revista de la Facultad de Derecho y Ciencias Políticas de la Universidad de Lima. Número 13. Lima.

GARCÍA BELAUNDE, Domingo (2005). " "La interpretación constitucional como problema". En: Eduardo Ferrer Mac Gregor (Coordinador) Interpretación Constitucional. Tomo I. Mexico: Editorial Porrúa.

GARCIA TOMA, Víctor (2005). "Teoría del Estado y Derecho Constitucional". Lima, Perú: Editorial Palestra S.A.

GASCON ABELLAN, Maria (1994). "La Justicia Constitucional: Entre legislación y jurisdicción". En Revista Española de Derecho Constitucional. Número 47, Mayo- Agosto de 1994. Madrid, España: Editada por Centro de Estudios Políticos Constitucionales.

GUASTINI, Ricardo (2001). "La constitucionalización del ordenamiento: el caso italiano". Estudios de Teoría constitucional. México: UNAM, Fontamara

GUASTINI, Ricardo (2016). Lecciones de Derecho Constitucional. Lima, Perú: Editorial Ediciones Legales E.I.R.L.

KELSEN, Hans (1974). La garantía jurisdiccional de la Constitución. Trad. Rolando Tamayo y Salmoran (Anuario Jurídico 1-1974). Instituto de Investigaciones Jurídicas de la Universidad Nacional Autónoma de México

LANDA ARROYO, César (2000). "Justicia constitucional y political questions". CEPC. En: Anuario Iberoamericano de Justicia Constitucional. $\mathrm{N}^{\circ} 4$. Madrid, España.

LANDA ARROYO, César (2011). Organización y funcionamiento del Tribunal Constitucional. Lima, Perú: Palestra Editores.

MANNING, John F. (2017). "Justice Scalia and the Idea of Judicial Restraint". En Michigan Law Review. Volm115. Issue 6. Consultado en: 22 de marzo del $2019 . \quad$ Recuperado de: http://michiganlawreview.org/wpvcontent/uplo ads/2017/04/115MichLRev747_Manning.pdf

MONROY CABRA, Marco Gerardo (2002). La interpretación constitucional. Bogotá, Colombia: Ediciones Librería del Profesional.

MONROY CABRA, Marco Gerardo (2004). "Necesidad e importancia de los tribunales constitucionales en un Estado social de Derecho". Biblioteca Jurídica Virtual del Instituto de Investigaciones Jurídicas de la UNAM. Consulta: 15 de agosto de 2017.
Recuperado de: https://revistascolaboracion.juridicas.unam.mx/index.php/anua rio-derechoconstitucional/article/view/30192/27256.

PEREZ TREMPS, Pablo (2003). "La Justicia Constitucional en la actualidad, especial referencia a América Latina". En Revista del Foro Constitucional Iberoamericano, N. 2, abril-junio 2003. Madrid, España: Biblioteca de la Universidad Carlos III de Madrid. Consulta: 01 de marzo del 2019. Recuperado de: https://earchivo.uc3m.es/handle/10016/11440

POSNER, Richard (1998). El Análisis Económico del Derecho. México D.F.: Editorial Fondo de Cultura Económica. Primera Edición en Español.

RAMOS NUÑEZ, Carlos (2018). La letra de la Ley, Historia de las Constituciones del Perú. Centro de Estudios Constitucionales del Tribunal Constitucional del Perú. Lima, Perú. Consulta: 10 de Marzo del 2019. Recuperado de: https://www.tc.gob.pe/wpcontent/uploads/2018/10/La-letra-de-la-ley.Historia-de-las-constituciones-del-Peru-TC.pdf

SAGÜES, Néstor Pedro (2009). "El Control de Convencionalidad en particular sobre las constituciones nacionales" En La Ley. Consulta: 19 de febrero del 2019. Recuperado de: https://laley.pe/doctrinalegal

SAGÜES, Néstor Pedro (2016). La Constitución bajo tensión. México: Editorial Instituto de Estudios Constitucionales del Estado de Querétaro.

SNYDER, Brad (2014)."The former clerks who nearly killed judicial restraint". En V-LEX. base de datos on line. ID. VLEX: VLEX-636160053. Consultado en: 22 de marzo del 2019.

STRAUSS, David (2011). "Originalism, conservatism, and judicial restraint". En Harvard Journal of Law \& Public Policy, Vol. 34 Núm. 1. En V-LEX. Base de datos on line. ID. VLEX: VLEX-636160053. Consultado en: 22 de marzo del 2019.

The U.S. National Archives and Records Administration 2019 (2019). " "La Constitución de Estados Unidos de América de 1787". Consultado en: 10 de marzo del 2019. Recuperado de: https://www.archives.gov/espanol/constitucion

TRIBE, Laurence H; DORF, Michael C (2010). "Interpretando la Constitución". Traducido por Jimena Aliaga Gamarra. Presentada y Revisada por César Landa Arroyo. Lima,Perú: Editorial Palestra Editores SAC 